\title{
The Effectiveness of Blood Metal Ions in Identifying Patients with Unilateral Birmingham Hip Resurfacing and Corail-Pinnacle Metal-on-Metal Hip Implants at Risk of Adverse Reactions to Metal Debris
}

\author{
Gulraj S. Matharu, BSc(Hons), MBChB, MRCS, MRes, Fiona Berryman, BSc(Hons), PhD, Lesley Brash, MSc, RN, \\ Paul B. Pynsent, PhD, Ronan B.C. Treacy, FRCS(Tr\&Orth), and David J. Dunlop, FRCS(Tr\&Orth) \\ Investigation performed at the Royal Orthopaedic Hospital, Birmingham, United Kingdom
}

\begin{abstract}
Background: We investigated whether blood metal ions could effectively identify patients with metal-on-metal hip implants with two common designs (Birmingham Hip Resurfacing [BHR] and Corail-Pinnacle) who were at risk of adverse reactions to metal debris.

Methods: This single-center, prospective study involved 598 patients with unilateral hip implants (309 patients with the BHR implant and 289 patients with the Corail-Pinnacle implant) undergoing whole blood metal ion sampling at a mean time of 6.9 years. Patients were classified into two groups, one that had adverse reactions to metal debris (those who had to undergo revision for adverse reactions to metal debris or those with adverse reactions to metal debris on imaging; $n=46)$ and one that did not $(n=552)$. Three metal ion parameters (cobalt, chromium, and cobalt-chromium ratio) were compared between groups. Optimal metal ion thresholds for identifying patients with adverse reactions to metal debris were determined using receiver operating characteristic analysis.
\end{abstract}

Results: All ion parameters were significantly higher $(p<0.0001)$ in the patients who had adverse reactions to metal debris compared with those who did not. Cobalt maximized the area under the curve for patients with the BHR implant (90.5\%) and those with the Corail-Pinnacle implant (79.6\%). For patients with the BHR implant, the area under the curve for cobalt was significantly greater than that for the cobalt-chromium ratio $(p=0.0005)$, but it was not significantly greater than that for chromium ( $p=0.8483$ ). For the patients with the Corail-Pinnacle implant, the area under the curve for cobalt was significantly greater than that for chromium ( $p=0.0004)$, but it was similar to that for the cobalt-chromium ratio $(p=0.8139)$. Optimal blood metal ion thresholds for identifying adverse reactions to metal debris varied between the two different implants. When using cobalt, the optimal threshold for identifying adverse reactions to metal debris was $2.15 \mu \mathrm{g} / \mathrm{L}$ for the BHR group and $3.57 \mu \mathrm{g} / \mathrm{L}$ for the Corail-Pinnacle group. These thresholds had good sensitivities ( $88.5 \%$ for the BHR group and $80.0 \%$ for the Corail-Pinnacle group) and specificities (84.5\% for the BHR group and $76.2 \%$ for the Corail-Pinnacle group), high negative predictive values (98.8\% for the BHR group and $98.1 \%$ for the Corail-Pinnacle group), and low positive predictive values (34.3\% for the BHR group and $20.0 \%$ for the Corail-Pinnacle group). The authority thresholds proposed by the United States

continued

Peer Review: This article was reviewed by the Editor-in-Chief and one Deputy Editor, and it underwent blinded review by two or more outside experts. It was also reviewed by an expert in methodology and statistics. The Deputy Editor reviewed each revision of the article, and it underwent a final review by the Editor-in-Chief prior to publication. Final corrections and clarifications occurred during one or more exchanges between the author(s) and copyeditors.

Disclosure: Four authors of this study (F.B., P.B.P., R.B.C.T., and D.J.D.) received, through their institutions, a grant from the manufacturer of the device that is the subject of this study. One author of this study (G.S.M.) received a grant from the Royal College of Surgeons of England and the Arthritis Research Trust, which provided this author's salary in the form of a surgical research fellowship. On the Disclosure of Potential Conflicts of Interest forms, which are provided with the online version of the article, one or more of the authors checked "yes" to indicate that the author had a relevant financial relationship in the biomedical arena outside the submitted work and "yes" to indicate that the author had other relationships or activities that could be perceived to influence, or have the potential to influence, what was written in this work. 
( $3 \mu \mathrm{g} / \mathrm{L}$ and $10 \mu \mathrm{g} / \mathrm{L}$ ) and the United Kingdom ( $7 \mu \mathrm{g} / \mathrm{L}$ ) missed more patients with adverse reactions to metal debris at $2.0 \%$ to $4.7 \%$ (twelve to twenty-eight patients) compared with our implant-specific thresholds at $1.2 \%$ (seven patients missed).

Conclusions: Patients who underwent metal-on-metal hip arthroplasty performed with unilateral BHR or Corail-Pinnacle implants and who had blood metal ions below our implant-specific thresholds were at low risk of adverse reactions to metal debris. These thresholds could be used to rationalize follow-up resources in asymptomatic patients. Analysis of cobalt alone is acceptable. Implant-specific thresholds were more effective than currently recommended fixed authority thresholds for identifying patients at risk of adverse reactions to metal debris requiring further investigation.

Level of Evidence: Diagnostic Level II. See Instructions for Authors for a complete description of levels of evidence.

A dverse reactions to metal debris have resulted in high failure rates of most metal-on-metal hip designs ${ }^{1-3}$, with poor outcomes also reported following the revision procedure for adverse reactions to metal debris ${ }^{4}$. To identify adverse reactions to metal debris early, regulatory authorities recommend regular follow-up of patients with metal-on-metal hip implants ${ }^{5-7}$.

Blood metal ion levels reflect in vivo metal-on-metal bearing wear $^{8}$ and are used for follow-up. The United Kingdom Medicines \& Healthcare products Regulatory Agency (MHRA) was the first to publish blood metal ion thresholds for concern in 2010, recommending cross-sectional imaging in patients with metal-on-metal hip implants if cobalt and/or chromium were $>7 \mu \mathrm{g} / \mathrm{L}^{9}$. Optimal cobalt and chromium thresholds for identifying poorly functioning metal-on-metal hip implants have ranged from 3.5 to $7 \mu \mathrm{g} / \mathrm{L}$ in subsequent studies, with thresholds having higher specificity than sensitivity ${ }^{10-14}$. A recent consensus statement from the United States focused on risk-stratifying patients with metal-on-metal implants to assist management, with blood metal ion results divided into groups of low risk $(<3 \mu \mathrm{g} / \mathrm{L})$, moderate risk (3 to $10 \mu \mathrm{g} / \mathrm{L})$, and high risk $(>10 \mu \mathrm{g} / \mathrm{L})^{15}$.

A recent study of 597 patients with unilateral Articular Surface Replacement (ASR) hip implants (DePuy Orthopaedics) showed different diagnostic test characteristics for blood metal ion levels between resurfacings and total hip replacements, with cobalt raised out of proportion to chromium in failed total hip replacements ${ }^{14}$. The blood cobalt-chromium ratio may therefore be useful in patients with metal-on-metal total hip replacements, although, to our knowledge, it has not been investigated. Although the recent work by Hart et al. was the first to assess diagnostic test characteristics of blood metal ions in total hip replacements, there were some important limitations $s^{14}$. The four main limitations were: (1) blood sampling during the bearing running-in phase ${ }^{16}$, (2) including all symptomatic patients who may have had no evidence of adverse reactions to metal debris in the failed group, (3) including patients whose revisions were performed for reasons other than adverse reactions to metal debris in the failed group, and (4) using arbitrary thresholds to assess blood metal ion diagnostic test characteristics. However, the authors recognized that their findings were only applicable to ASR hip implants, which represent the worst-performing device ${ }^{1718}$. Given that implant failure rates vary among metal-on-metal hip designs ${ }^{17}$, we hypothesized that blood metal ion thresholds for identifying adverse reactions to metal debris would also differ among implant designs.

This study involved patients with two commonly implanted metal-on-metal hip designs: Birmingham Hip Resurfacing (BHR;
Smith \& Nephew) and Corail-Pinnacle (DePuy Synthes) total hip replacement. The study had two aims: (1) to investigate whether blood metal ion thresholds could effectively identify patients at risk of adverse reactions to metal debris, and (2) to determine whether the cobalt-chromium ratio, when compared with using cobalt and chromium alone, was any more effective for identifying patients with adverse reactions to metal debris.

\section{Materials and Methods}

A prospective, single-center, cohort study of consecutive patients receiving A current-generation metal-on-metal hip replacements was performed. This study was registered with the hospital board. Ethical approval was not required because patients were assessed according to published guidelines ${ }^{5}$ and were not specifically evaluated for this study.

\section{Metal-on-Metal Hip Replacement}

Between August 1997 and May 2013, 3988 patients at one specialist center received 4816 primary metal-on-metal hip implants (3792 resurfacing and 1024 total hip replacement). Of the 3792 resurfacing implants, 87\% (3299) were BHR implants, which are produced from an as-cast high-carbon cobalt-chromium-molybdenum alloy and represent the most commonly implanted resurfacing device worldwide ${ }^{19}$. Five different metal-on-metal total hip replacement designs were implanted at this center on the basis of surgeon preference; the majority (578 [56\%]) of these 1024 total hip replacements were Corail-Pinnacle implants. The Corail femoral stem is a fully hydroxyapatite-coated titanium alloy stem with a 12/14 taper onto which a cobalt-chromium alloy femoral head is impacted, which articulates with a metal liner. The BHR implant and Corail-Pinnacle total hip replacement were the only implant designs assessed in this study, with information regarding patient selection, operative technique, and routine follow-up described previously ${ }^{20-22}$.

\section{Follow-up}

This institution's routine follow-up of patients with metal-on-metal hip implants was adapted according to MHRA alerts ${ }^{5,9}$. In addition to clinical assessment (history, examination, anteroposterior pelvic radiographs, and Oxford Hip Score questionnaire $^{23}$ ), all symptomatic patients underwent blood metal ion sampling and cross-sectional imaging. All asymptomatic patients who underwent total hip replacement and asymptomatic patients with BHR implants who had adverse reactions to metal debris risk factors (small femoral components, malpositioned acetabular components, radiographic evidence suggesting implant failure) underwent clinical assessment with blood metal ions ${ }^{22,24,25}$. In line with MHRA guidance, all asymptomatic patients with blood cobalt and/or chromium ion levels of $>7 \mu \mathrm{g} / \mathrm{L}$ (the MHRA upper limit) underwent cross-sectional imaging ${ }^{5}$. The institution's protocol recommends ultrasound for symptomatic patients and metal artifact reduction sequence magnetic resonance imaging (MRI) for asymptomatic patients. As asymptomatic patients were likely to require repeat imaging, serial MRIs were considered easier to compare than ultrasound images. If MRI was contraindicated, ultrasound was used. By May 2013, 1336 patients with 1557 metal-on-metal hip implants had undergone blood metal ion sampling. These patients were initially eligible for study inclusion. 


\section{TABLE I Patient Demographic Characteristics for the Study Cohort (N = 598)}

\begin{tabular}{|c|c|c|c|c|}
\hline Parameter & All Patients & $\begin{array}{c}\text { Patients with } \\
\text { Adverse Reactions } \\
\text { to Metal Debris }\end{array}$ & $\begin{array}{l}\text { Patients without } \\
\text { Adverse Reactions } \\
\text { to Metal Debris }\end{array}$ & P Value \\
\hline No. of patients & $598(100 \%)$ & $46(8 \%)$ & $552(92 \%)$ & \\
\hline Sex* & & & & $0.0226 \dagger$ \\
\hline Female & 313 & 32 & 281 & \\
\hline Age at the time of the blood test $\neq(y r)$ & 61.7 (19.6 to 93.8$)$ & 58.8 (32.8 to 77.0$)$ & 62.0 (19.6 to 93.8$)$ & 0.0552 \\
\hline $\begin{array}{l}\text { Time between primary arthroplasty and blood } \\
\text { test } \neq(y r)\end{array}$ & $6.9(1.0$ to 16.2$)$ & $7.3(2.1$ to 14.3$)$ & 6.9 (1.0 to 16.2$)$ & 0.3367 \\
\hline \multicolumn{5}{|l|}{ BHR group (52\%) } \\
\hline No. of patients & 309 (100\%) & $26(8 \%)$ & $283(92 \%)$ & \\
\hline $\begin{array}{l}\text { Time between primary arthroplasty and blood } \\
\text { test } \neq(y r)\end{array}$ & 7.8 (1.0 to 16.2$)$ & 8.9 (3.5 to 14.3$)$ & 7.6 (1.0 to 16.2$)$ & 0.0742 \\
\hline \multicolumn{5}{|l|}{ Corail-Pinnacle group (48\%) } \\
\hline No. of patients & 289 (100\%) & $20(7 \%)$ & 269 (93\%) & \\
\hline Sex* & & & & 0.5967 \\
\hline Female & 168 & 10 & 158 & \\
\hline Male & 121 & 10 & 111 & \\
\hline Age at the time of the blood test $\neq(y r)$ & 66.6 (40.7 to 93.8$)$ & 64.7 (47.2 to 77.0$)$ & $66.8(40.7$ to 93.8$)$ & 0.4912 \\
\hline $\begin{array}{l}\text { Time between primary arthroplasty and blood } \\
\text { test } \neq(y r)\end{array}$ & 6.0 (1.9 to 10.1$)$ & 5.3 (2.1 to 8.9$)$ & 6.0 (1.9 to 10.1$)$ & 0.1163 \\
\hline
\end{tabular}

\section{TABLE II Blood Metal Ion Parameters for All Study Groups}

\begin{tabular}{|c|c|c|c|c|}
\hline Parameter & All Patients & $\begin{array}{l}\text { Patients with Adverse } \\
\text { Reactions to Metal Debris }\end{array}$ & $\begin{array}{l}\text { Patients without Adverse } \\
\text { Reactions to Metal Debris }\end{array}$ & P Value \\
\hline All patients* (100\%) & $598(100 \%)$ & $46(8 \%)$ & 552 (92\%) & \\
\hline Chromium $\dagger(\mu \mathrm{g} / L)$ & 1.40 (0.99 to 2.44$)$ & 4.37 (1.68 to 27.99 ) & $1.40(0.94$ to 2.18$)$ & $<0.0001 \ddagger$ \\
\hline Cobalt-chromium ratio $†$ & 0.92 (0.56 to 1.46$)$ & 1.73 (1.04 to 2.86$)$ & 0.86 (0.55 to 1.35$)$ & $<0.0001 \neq$ \\
\hline Chromium $\dagger(\mu \mathrm{g} / L)$ & 1.56 (1.09 to 2.50$)$ & 9.91 (3.12 to 35.36$)$ & 1.46 (1.04 to 2.16$)$ & $<0.0001 \ddagger$ \\
\hline Cobalt-chromium ratio $†$ & 0.71 (0.52 to 1.00$)$ & 1.16 (0.78 to 1.94$)$ & 0.69 (0.51 to 0.95$)$ & $<0.0001 \ddagger$ \\
\hline Corail-Pinnacle group* (48\%) & $289(100 \%)$ & $20(7 \%)$ & 269 (93\%) & \\
\hline Cobalt $\dagger(\mu \mathrm{g} / L)$ & 2.18 (0.77 to 3.72$)$ & 4.66 (3.66 to 9.56$)$ & $2.12(0.71$ to 3.54$)$ & $0.0001 \neq$ \\
\hline Chromium $\dagger(\mu g / L)$ & 1.30 (0.88 to 2.29$)$ & 1.69 (0.76 to 3.49$)$ & $1.30(0.88$ to 2.27$)$ & 0.1950 \\
\hline
\end{tabular}




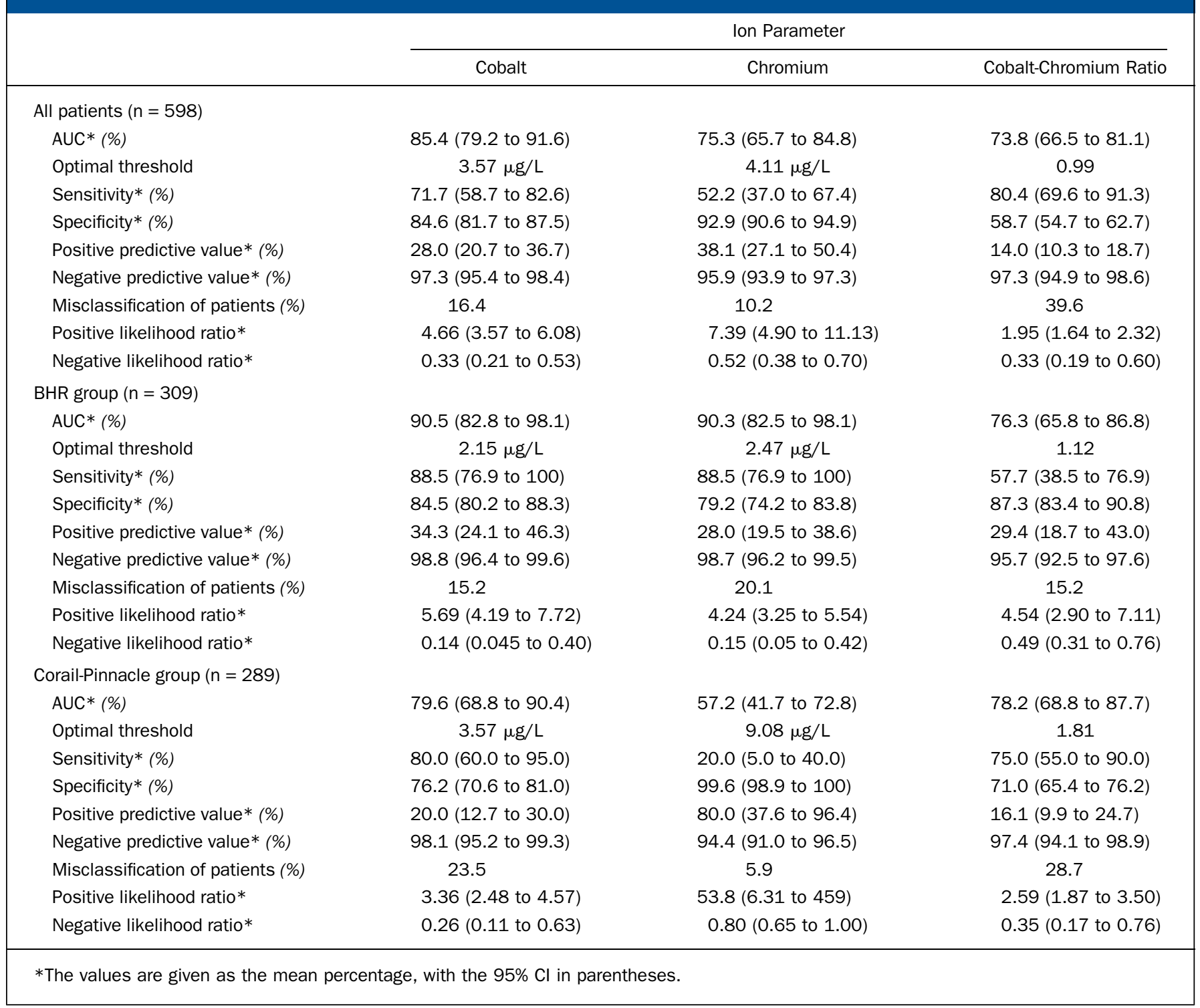

\section{Inclusion and Exclusion Criteria}

Patients with unilateral, primary large-diameter $(\geq 36-\mathrm{mm})$ BHR and CorailPinnacle total hip replacement designs with blood sampling performed at least one year following arthroplasty were included. Patients who underwent revision after blood sampling and who did not have evidence of adverse reactions to metal debris (infection, periprosthetic fracture, aseptic loosening, unexplained pain, dislocation) were excluded to reduce the risk of confounding factors when devising thresholds specific for adverse reactions to metal debris. In all such cases, the intraoperative revision findings, histopathology, and microbiology confirmed the absence of adverse reactions to metal debris.

\section{Definitions}

Patients eligible for final inclusion $(\mathrm{n}=598)$ were divided into two groups based on their status in September 2014. The group with adverse reactions to metal debris $(n=46)$ included all patients who underwent revision to treat such adverse reactions $(\mathrm{n}=30)$, those awaiting revision to treat such adverse reactions $(\mathrm{n}=2)$, and those with adverse reactions to metal debris confirmed on cross-sectional imaging (evidence of periprosthetic effusions and pseudotumors $)^{26-28}$ who were under surveillance but not listed for revision because of clinician and/or patient preference $(n=14)$. A revision surgical procedure was recommended on the basis of findings from the clinical assessment, radiographs, and cross-sectional imaging. Blood metal ions alone were not used to decide on revision, as previously recommended ${ }^{14}$. The group without adverse reactions to metal debris $(n=552)$ consisted of all patients with primary metalon-metal hip implants in situ and no evidence of adverse reactions to metal debris on cross-sectional imaging. Symptoms were not used to stratify patients, given that adverse reactions to metal debris frequently occur in asymptomatic patients $^{26,27}$.

\section{Blood Metal Ion Analysis}

Whole blood was collected from the antecubital vein of patients for metal ion analysis. Venous blood was collected in trace element tubes containing sodium heparin with methods used to minimize contamination risk ${ }^{29}$. All samples were analyzed in an MHRA-approved laboratory that regularly participates in the 
The Journal of Bone \& Joint Surgery $\cdot$ JBjS. Org Volume 98-A • Number 8 · April 20, 2016
The Role of Blood Metal Ions in Patients with Unilateral Metal-on-Metal Hip Implants

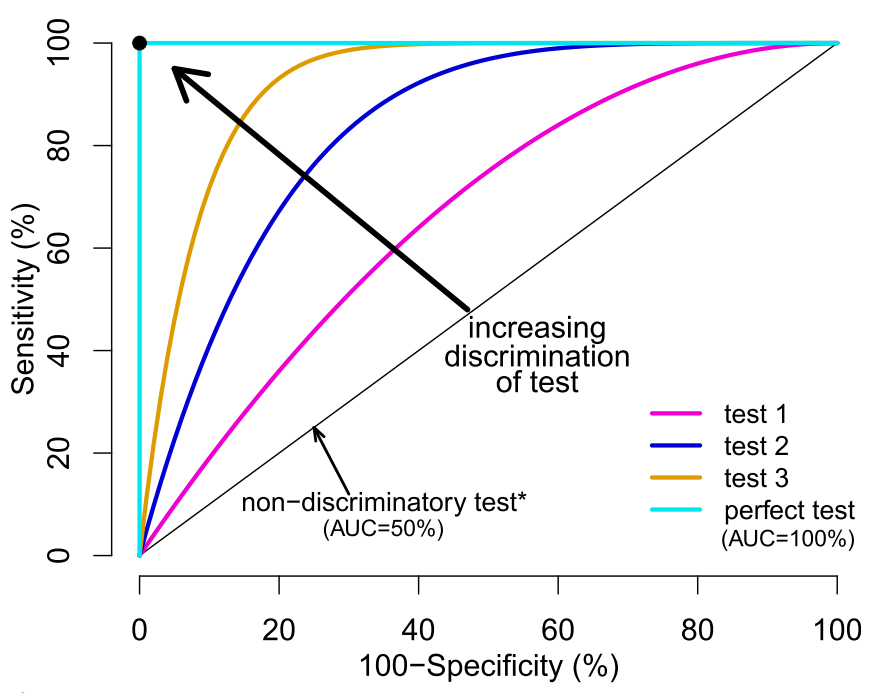

Fig. 1

An explanation of ROC analysis with example lines for varying diagnostic ability. The black solid circle in the top left corner represents the perfect diagnostic threshold, with sensitivity and specificity both equaling $100 \%$. The asterisk indicates that a non-discriminatory test is no better than a chance finding.

Trace Elements External Quality Assessment Scheme, with excellent measurement accuracy and reproducibility reported ${ }^{30}$. Cobalt and chromium concentrations were measured using an inductively coupled plasma mass spectrometer (Agilent $7500 \mathrm{cx}$; Agilent Technologies). The limit of detection was $0.06 \mu \mathrm{g} / \mathrm{L}$ and the reporting limit was $0.6 \mu \mathrm{g} / \mathrm{L}$.

\section{Statistical Analysis}

The three blood metal ion parameters of interest were cobalt, chromium, and the cobalt-chromium ratio. The cobalt-chromium ratio is non-dimensional and was calculated by dividing cobalt concentration by chromium concentration for each patient. To compare the logarithms of the three metal ion parameters between the group that had adverse reactions to metal debris and the group that did not, unpaired $t$ testing was used. Significance was set at $\mathrm{p}<0.05$. The logarithm was necessary to transform the asymmetric blood metal ion distributions to approximately normal distributions as recommended ${ }^{31}$.

Receiver operating characteristic (ROC) analysis is an established method of assessing the performance of a diagnostic test ${ }^{32}$. The ROC curve is drawn by plotting sensitivity (true positive rate) against $1-$ specificity (or 100 - specificity if presented as a percentage; also called a false positive rate) for all possible test thresholds. A useful test will produce a curve that lies to the left of the $45^{\circ}$ line (Fig. 1). The further the curve is toward the top left corner, the higher the area under the curve (AUC) and the better the discriminatory performance of the test. An AUC of 100\% represents a test with perfect discrimination. An AUC of 50\% represents a non-discriminatory test. ROC analysis can also be used to define the optimal threshold to maximize discriminatory ability for any given test.

We used ROC analysis to determine the optimal blood metal ion thresholds for identifying patients with hip implants who had adverse reactions to metal debris. This is a standard method for selecting the threshold maximizing the sum of the specificity and sensitivity. This corresponds to the point on the curve nearest to the top left corner. Sensitivity, specificity, positive and negative predictive values, and positive and negative likelihood ratios were calculated with their 95\% confidence intervals (95\% CIs) for the optimal thresholds for each of the three blood metal ion parameters. Misclassification rates were also calculated for all thresholds. The DeLong test was used to compare the AUCs among the different metal ion parameters ${ }^{33}$.

\section{Results}

7 here were 598 patients with metal-on-metal hip implants (309 BHR implants and 289 Corail-Pinnacle implants) eligible for inclusion (Table I).

\section{Blood Metal Ions}

The three blood metal ion parameters were summarized (Table II) and their distribution was illustrated according to implant design (Fig. 2). Patients with the Corail-Pinnacle implant had significantly higher cobalt concentrations $(\mathrm{p}=0.0010)$ and cobalt-chromium ratios $(\mathrm{p}<0.0001)$ compared with patients with the BHR implant. Patients with the BHR implant had significantly higher chromium concentrations $(p=0.0012)$ compared with patients with the Corail-Pinnacle implant (Fig. 2). For the whole cohort, all three blood metal ion parameters were significantly higher (all $\mathrm{p}<$ 0.0001 ) in the group that had adverse reactions to metal debris compared with the group that did not (Table II).

\section{Threshold Analysis}

Optimal blood metal ion thresholds for discriminating between patients with hip implants who had adverse reactions to metal debris and those patients who did not varied between the two different implant designs and were also dependent on the specific metal ion parameter used (Table III).

\section{Thresholds for Patients with BHR Implants}

Compared with the other two ion parameters, cobalt concentration produced the maximum AUC of $90.5 \%$ (95\% CI, 82.8\% to $98.1 \%$ ) for patients with BHR implants. The cobalt AUC was significantly greater than the cobalt-chromium ratio $\mathrm{AUC}(\mathrm{p}=$ 0.0005) (Table III and Fig. 3), but not significantly greater than the chromium AUC ( $\mathrm{p}=0.8483$ ). The cobalt threshold for identifying patients in the BHR group with adverse reactions to metal debris providing the optimal diagnostic test characteristics was $2.15 \mu \mathrm{g} / \mathrm{L}$ (88.5\% sensitivity, $84.5 \%$ specificity, $34.3 \%$ positive predictive value, and $98.8 \%$ negative predictive value) (Table III, Appendix).
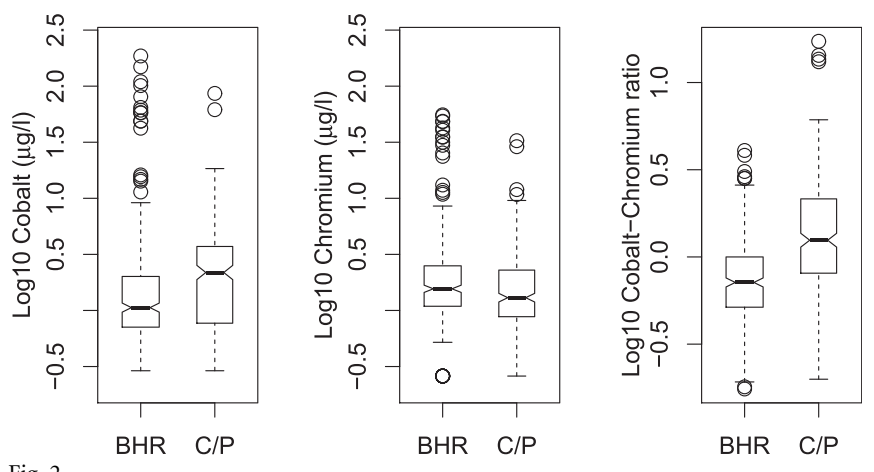

Box plots showing the median and interquartile range for blood metal ion parameters stratified by implant design. The whiskers show the range covered by data points up to 1.5 times the interquartile range and outliers beyond this range are shown as open circles. BHR = Birmingham Hip Resurfacing and $\mathrm{C} / \mathrm{P}=$ Corail-Pinnacle total hip replacement. 


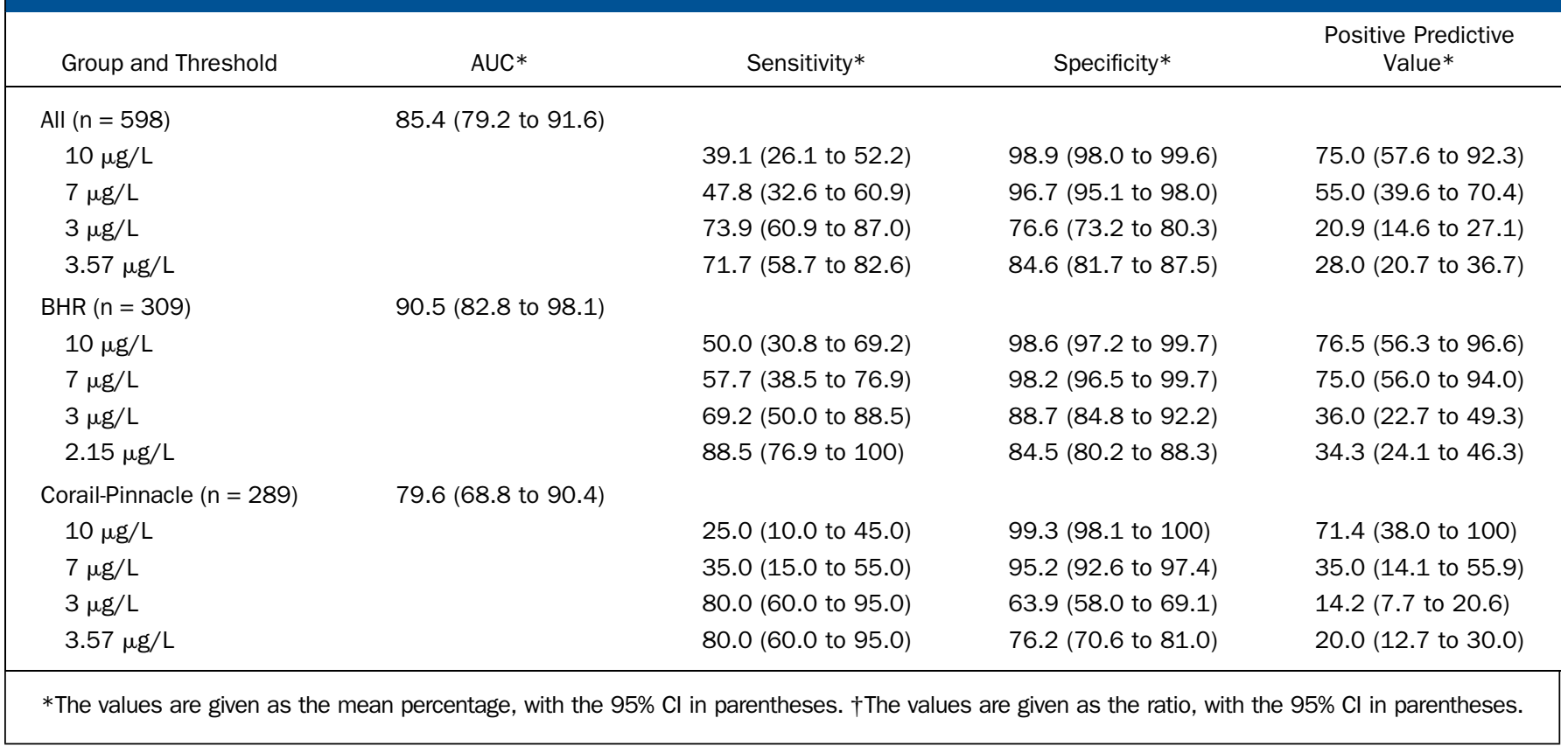

\section{Thresholds for Patients with Corail-Pinnacle Implants} Compared with the other metal ion parameters, cobalt concentration produced the maximum AUC of $79.6 \%$ (95\% CI, $68.8 \%$ to 90.4\%) for patients with Corail-Pinnacle total hip replacements. The cobalt AUC was significantly greater than that for chromium $(\mathrm{p}=0.0004)$, but not significantly different from the cobaltchromium ratio AUC ( $\mathrm{p}=0.8139)$ (Table III and Fig. 4). The cobalt threshold for identifying Corail-Pinnacles with adverse reactions to metal debris providing the optimal diagnostic test characteristics was $3.57 \mu \mathrm{g} / \mathrm{L}$ ( $80.0 \%$ sensitivity, $76.2 \%$ specificity, $20.0 \%$ positive predictive value, and $98.1 \%$ negative predictive value) (Table III).

\section{Regulatory Authority Blood Metal Ion Thresholds}

Blood metal ion thresholds for concern proposed by the United States $(3 \mu \mathrm{g} / \mathrm{L} \text { and } 10 \mu \mathrm{g} / \mathrm{L})^{15}$ and the U.K. MHRA $(7 \mu \mathrm{g} / \mathrm{L})^{5}$ were applied to the cohort and were compared with our implantspecific thresholds in terms of the diagnostic test characteristics for identifying patients with adverse reactions to metal debris and the proportion of patients with adverse reactions to metal debris who were not identified by each threshold. As our work demonstrated that cobalt alone provided optimal diagnostic test characteristic and AUC results, we only used cobalt ion data for this comparison.

Compared with fixed regulatory authority thresholds, the implant-specific thresholds for cobalt provided the optimal balance of sensitivity and specificity and higher negative predictive values, but generally lower positive predictive values (Table IV). Applying implant-specific thresholds to the cohort resulted in seven patients with adverse reactions to metal debris being missed (1.2\% of the cohort [three patients in the BHR group and four patients in the Corail Pinnacle group]). More patients with adverse reactions to metal debris were missed when using fixed regulatory thresholds. With the threshold of $3 \mu \mathrm{g} / \mathrm{L}$, twelve patients (2.0\%) were missed; with the threshold of $7 \mu \mathrm{g} / \mathrm{L}$, twenty-four patients $(4.0 \%)$ were missed; and with the threshold of $10 \mu \mathrm{g} / \mathrm{L}$, twentyeight patients (4.7\%) were missed. Using the regulatory authority threshold with the lowest number of missed patients $(3 \mu \mathrm{g} / \mathrm{L})$

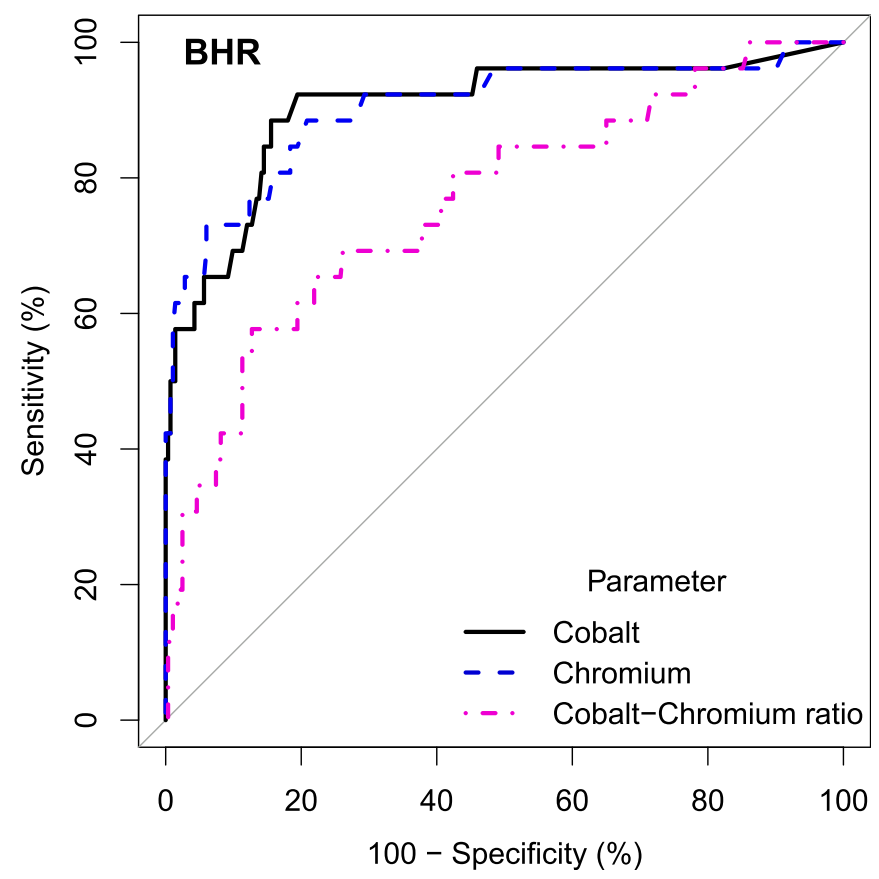

Fig. 3

ROC curve showing the ability of three blood metal ion parameters to distinguish between patients with a Birmingham Hip Resurfacing (BHR) implant who had adverse reactions to metal debris and those who did not. 


\section{TABLE IV (continued)}

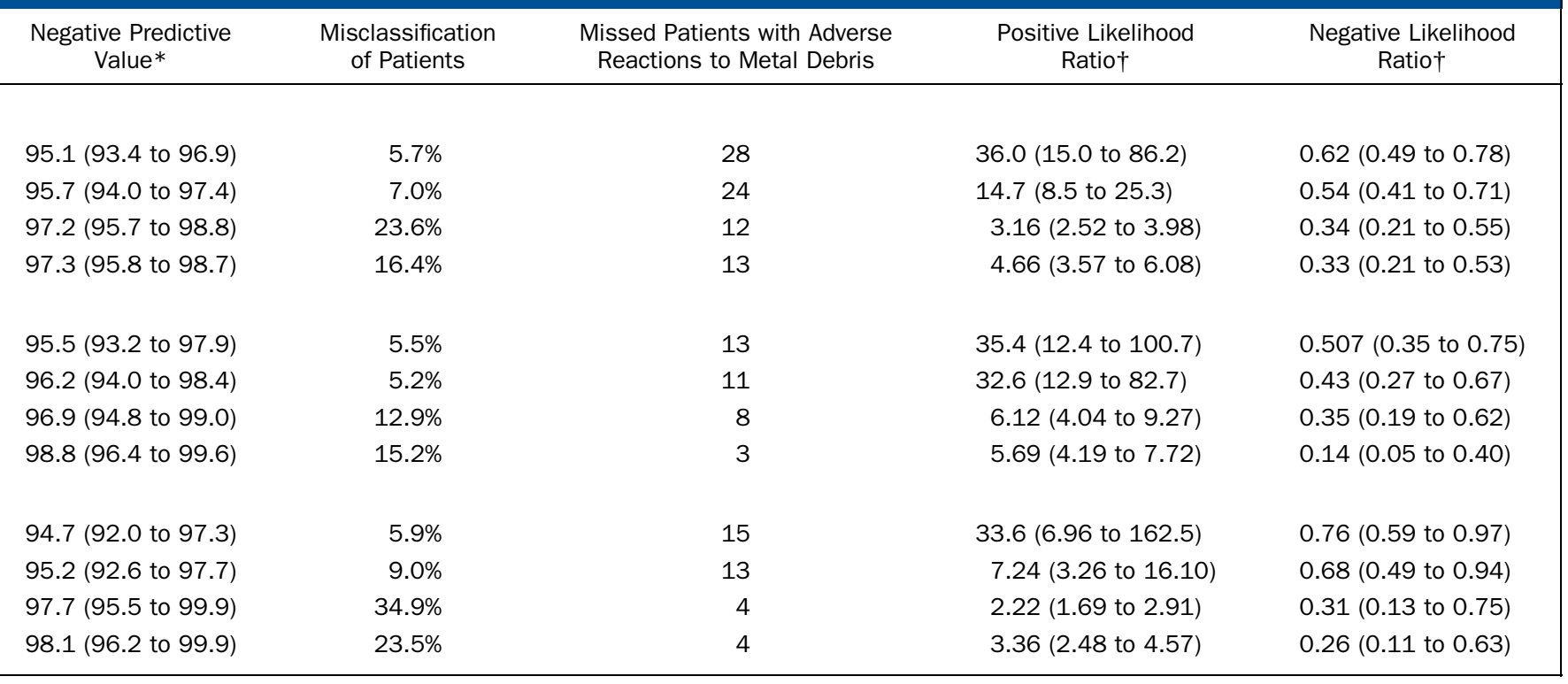

resulted in $71 \%$ more missed patients with adverse reactions to metal debris compared with patients missed when using implantspecific thresholds, although this difference was not significant ( $p=0.074$; McNemar test). Significantly more patients with adverse reactions to metal debris were missed when using thresholds of $7 \mu \mathrm{g} / \mathrm{L}(\mathrm{p}=0.0001)$ and $10 \mu \mathrm{g} / \mathrm{L}(\mathrm{p}=0.0001)$ compared with patients missed when using implant-specific thresholds.

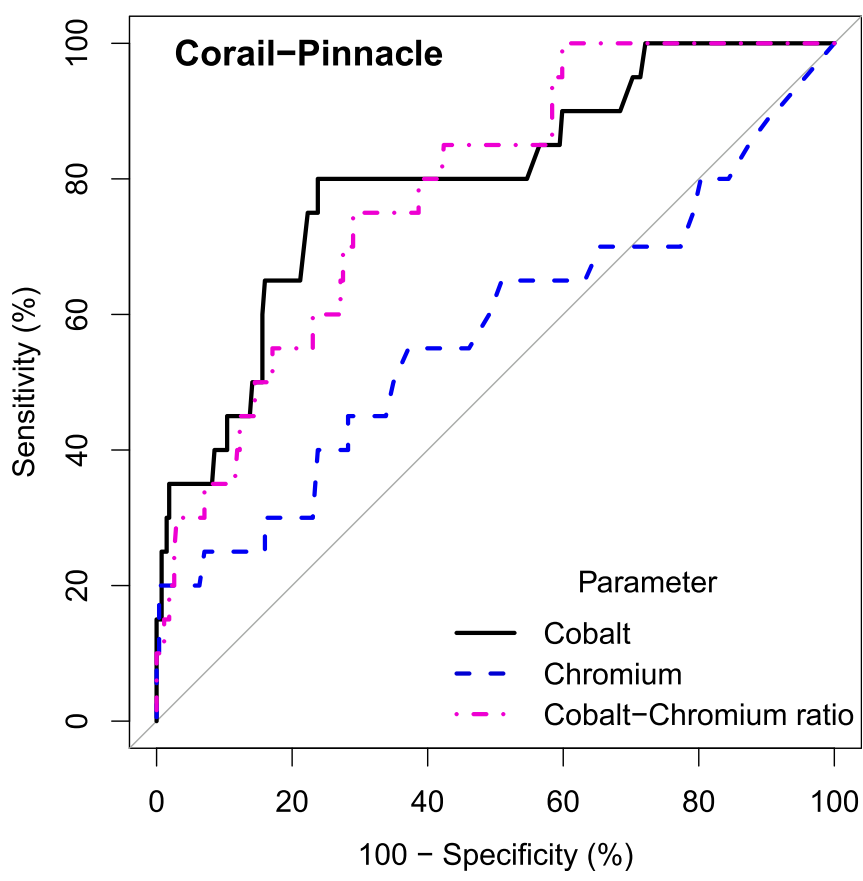

Fig. 4

ROC curve showing the ability of three blood metal ion parameters to distinguish between patients with a Corail-Pinnacle total hip replacement who had adverse reactions to metal debris and those who did not.
Discussion

$7 \mathrm{o}$ our knowledge, this represents the largest study to assess 1 whether blood metal ions could effectively identify patients with metal-on-metal hip implants with two common designs who are at risk of adverse reactions to metal debris, and it also represents the first study to formally analyze the cobalt-chromium ratio. Patients with unilateral BHR and Corail-Pinnacle hip replacements who had blood metal ions below implant-specific thresholds $(2.15 \mu \mathrm{g} / \mathrm{L}$ for cobalt for the BHR group and $3.57 \mu \mathrm{g} / \mathrm{L}$ for cobalt for the Corail-Pinnacle group) were at low risk of adverse reactions to metal debris. These implant-specific thresholds were more effective compared with the fixed thresholds currently recommended $^{5,15}$. Cobalt alone produced optimal results for identifying adverse reactions to metal debris in both implant systems.

The observation that implant-specific thresholds exist for identifying patients with metal-on-metal hip implants who have adverse reactions to metal debris is novel. Of the three blood metal ion parameters assessed, cobalt proved to be the best ion to test for in both the BHR group and the Corail-Pinnacle group. Our data demonstrated that cobalt ions were most effective for identifying patients at a low risk of adverse reactions to metal debris, rather than identifying patients with adverse reactions to metal debris. We consider this to be the most important finding because clinically we wish to rule out patients with this complication to allow us to focus on the subgroup of patients who may have adverse reactions to metal debris. Those asymptomatic patients above the implant-specific thresholds require crosssectional imaging; however, those patients below the implantspecific thresholds are at a low risk of adverse reactions to metal debris. Provided that patients have normal clinical examinations and radiographs, they can be reassured and can be excluded from regular follow-up regimens ${ }^{5-7}$. In the current study, $78 \%$ of patients with BHR implants had a cobalt level below the new implant-specific threshold of $2.15 \mu \mathrm{g} / \mathrm{L}$. As most patients with 
The Journal of Bone \& Joint Surgery $\cdot$ JbJs.org Volume 98-A · Number 8 · April 20, 2016
The Role of Blood Metal Ions in Patients with Unilateral Metal-on-Metal Hip Implants
BHR implants are asymptomatic, even at long-term followup $^{34-36}$, reducing follow-up regularity in this large cohort would yield substantial financial and resource savings.

Our implant-specific thresholds are lower than those previously proposed for a range of poorly functioning metal-on-metal hip designs $(3.5 \text { to } 7 \mu \mathrm{g} / \mathrm{L})^{10-14}$. These implant-specific thresholds provide more balanced sensitivity and specificity compared with those in previous studies, which showed good specificity but poor sensitivity ${ }^{10,13,14}$. We consider the definition used for failure to be the main factor explaining these observed differences between studies. The definition of failure in previous reports had included both symptomatic patients, regardless of cause, and patients with implants revised for reasons other than adverse reactions to metal debris $^{10,13,14}$. Our definition for identifying metal-on-metal hip replacement-related complications was more robust; therefore, the implant-specific thresholds are specific for adverse reactions to metal debris.

The application of fixed metal ion thresholds recommended by U.S. and U.K. authorities ${ }^{5,15}$ missed more patients with hip implants who had adverse reactions to metal debris compared with patients missed when using implant-specific thresholds. The fixed thresholds of $7 \mu \mathrm{g} / \mathrm{L}$ (the U.K. threshold and also recommended recently by Hart et al. in patients with ASR hip implants) ${ }^{14}$ and $10 \mu \mathrm{g} / \mathrm{L}$ (the U.S. upper threshold) missed significantly more patients with hip implants who had adverse reactions to metal debris compared with implant-specific thresholds. When using $3 \mu \mathrm{g} / \mathrm{L}$ (the U.S. lower threshold), the difference was not significant; however, this "low-risk" threshold $^{15}$ missed $71 \%$ more patients with hip implants who had adverse reactions to metal debris compared with patients missed when implant-specific thresholds were used. We consider this difference clinically important given the potentially destructive nature of adverse reactions to metal debris and poor outcomes reported following revision of both metal-on-metal hip resurfacings and stemmed total hip replacements ${ }^{4}$. It is important not to miss patients with this potentially destructive condition; therefore, minimizing the false-negative rate is clinically beneficial. Although current guidelines recommend using fixed blood metal ion thresholds ${ }^{5,15}$, we observed that implant-specific thresholds provided more accurate information for the two implant systems assessed in this study. In light of these findings, it is hoped that implant-specific thresholds will be developed for other implant designs in the future.

Of the three blood metal ion parameters investigated, cobalt was the best ion to test for in both the BHR implant group and the Corail-Pinnacle implant group. Differences in chromium and the cobalt-chromium ratio between arthroplasties are likely to relate to implant design, with previous studies demonstrating that wear debris and/or corrosion at the taper-head junction in metal-on-metal total hip replacements produces cobalt preferentially over chromium ${ }^{37-39}$. Our data suggest that measuring blood chromium in patients with unilateral BHR and Corail-Pinnacle replacements provides no additional information compared with cobalt alone. Given the financial burden associated with follow-up for patients with metal-on-metal implants ${ }^{40}$, we recommend measuring only blood cobalt, which confirms the recommendations of others ${ }^{6}$. Sampling cobalt alone would save one-third of blood test costs at our laboratory (saving \$15.40 per test).

This study had limitations. The proposed implant-specific thresholds only apply to patients with unilateral BHR and CorailPinnacle implants. These two implant groups were also heterogeneous given the different patient selection criteria described for each procedure $\mathrm{e}^{20-22}$. Furthermore, this was a cross-sectional study with blood metal ions sampled once. Although we cannot make recommendations regarding intervals for repeat blood testing, current evidence suggests that annual blood sampling would be the most frequent for asymptomatic patients with metal-on-metal total hip replacements ${ }^{41}$; however, patients with BHR implants who have low initial ion levels are unlikely to need repeat testing within this time frame, if at all, provided that they are asymptomatic $^{42}$. It is also recognized that there is currently a lack of interlaboratory standardization for blood metal ion analysis that may limit the generalizability of our findings. Finally, in line with current recommendations $^{5,6}$ and other centers ${ }^{13,43,44}$, not all asymptomatic patients underwent cross-sectional imaging. Only asymptomatic patients with blood metal ions of $>7 \mu \mathrm{g} / \mathrm{L}$ underwent such imaging. Although this reflects modern follow-up programs in which resources must be rationalized, some asymptomatic patients not undergoing cross-sectional imaging may have had silent adverse reactions to metal debris, although they would have been classified as patients without adverse reactions to metal debris. However, this effect was mitigated by including patients with adverse reactions to metal debris on imaging but still under surveillance as arthroplasty failures.

In conclusion, patients who underwent metal-on-metal hip arthroplasty with unilateral BHR and Corail-Pinnacle implants and who had blood metal ions below our proposed implantspecific thresholds were at a low risk of adverse reactions to metal debris. These implant-specific thresholds could be used to rationalize follow-up resources in asymptomatic patients with these two implant designs. Analysis of cobalt alone is acceptable for both implant systems. Fixed blood metal ion thresholds currently recommended by regulatory authorities ${ }^{5,15}$ were associated with an increased risk of missing patients who have adverse reactions to metal debris. Implant-specific thresholds were therefore more effective for identifying patients with unilateral BHR and CorailPinnacle implants who were at risk of adverse reactions to metal debris and required further investigation.

\section{Appendix}

eA A description of an analysis of the male and female coeA horts in the BHR group and a table showing a summary of the ROC analysis for cobalt in patients with the BHR implant stratified by sex are available with the online version of this article as a data supplement at jbjs.org.

Gulraj S. Matharu, BSc(Hons), MBChB, MRCS, MRes ${ }^{1}$

Fiona Berryman, $\mathrm{BSc}$ (Hons), $\mathrm{PhD}^{1}$

Lesley Brash, MSc, $\mathrm{RN}^{1}$ 
The Journal of Bone \& Joint Surgery $\cdot$ JBjS. org Volume 98-A · Number 8 · April 20, 2016
The Role of Blood Metal Ions in Patients with Unilateral Metal-on-Metal Hip Implants
Paul B. Pynsent, $\mathrm{PhD}^{1}$

Ronan B.C. Treacy, FRCS(Tr\&Orth $)^{1}$

David J. Dunlop, FRCS(Tr\&Orth $)^{1}$

${ }^{1}$ The Royal Orthopaedic Hospital,

Birmingham, United Kingdom
E-mail address for G.S. Matharu: gsm@doctors.org.uk

E-mail address for F. Berryman: fiona.berryman@nhs.net

E-mail address for L. Brash: lesley.brash@nhs.net

E-mail address for P.B. Pynsent: p.b.pynsent@bham.ac.uk

E-mail address for R.B.C. Treacy: trea40@aol.com

E-mail address for D.J. Dunlop: david.dunlop1@nhs.net

\section{References}

1. Langton DJ, Jameson SS, Joyce TJ, Gandhi JN, Sidaginamale R, Mereddy P, Lord $\mathrm{J}$, Nargol AV. Accelerating failure rate of the ASR total hip replacement. J Bone Joint Surg Br. 2011 Aug;93(8):1011-6.

2. Smith AJ, Dieppe P, Vernon K, Porter M, Blom AW; National Joint Registry of England and Wales. Failure rates of stemmed metal-on-metal hip replacements: analysis of data from the National Joint Registry of England and Wales. Lancet. 2012 Mar 31;379(9822):1199-204. Epub 2012 Mar 13.

3. Smith AJ, Dieppe P, Howard PW, Blom AW; National Joint Registry for England and Wales. Failure rates of metal-on-metal hip resurfacings: analysis of data from the National Joint Registry for England and Wales. Lancet. 2012 Nov 17;380 (9855):1759-66. Epub 2012 Oct 2.

4. Matharu GS, Pynsent PB, Dunlop DJ. Revision of metal-on-metal hip replacements and resurfacings for adverse reaction to metal debris: a systematic review of outcomes. Hip Int. 2014 Jul-Aug;24(4):311-20. Epub 2014 May 23.

5. Medicines \& Healthcare products Regulatory Agency (MHRA). Medical device alert: all metal-on-metal (MoM) hip replacements. 2012 Jun 25. https://assets. digital.cabinet-office.gov.uk/media/5485abf6ed915d4c10000273/con155767. pdf. Accessed 2015 Jul 17.

6. European Federation of National Associations of Orthopaedics and Traumatology. Consensus statement "Current evidence on the management of metal-on-metal bearings." 2012. http://www.efort.org/communications/pdf/ 2012_05_10_MoM_Consensus_statement.pdf. Accessed 2015 Jul 17.

7. U.S. Food and Drug Administration. Medical devices. Metal-on-metal hip implants. Information for orthopaedic surgeons. 2013. http://www.fda.gov/ MedicalDevices/ProductsandMedicalProcedures/ImplantsandProsthetics/ MetalonMetalHiplmplants/ucm241667.htm. Accessed 2015 Jul 17.

8. De Smet K, De Haan R, Calistri A, Campbell PA, Ebramzadeh E, Pattyn C, Gill HS Metal ion measurement as a diagnostic tool to identify problems with metal-on-metal hip resurfacing. J Bone Joint Surg Am. 2008 Nov;90(Suppl 4):202-8.

9. Medicines \& Healthcare products Regulatory Agency (MHRA). Medical device alert: ASR ${ }^{\mathrm{TM}}$ hip replacement implant manufactured by DePuy International Ltd. 2010 Apr 22. https://www.gov.uk/drug-device-alerts/medical-device-alert-metalon-metal-mom-hip-replacements-updated-advice-with-patient-follow-ups. Accessed 2015 Jul 17.

10. Hart AJ, Sabah SA, Bandi AS, Maggiore P, Tarassoli P, Sampson B, A Skinner J. Sensitivity and specificity of blood cobalt and chromium metal ions for predicting failure of metal-on-metal hip replacement. J Bone Joint Surg Br. 2011 Oct;93 (10):1308-13.

11. Malek IA, King A, Sharma H, Malek S, Lyons K, Jones S, John A. The sensitivity, specificity and predictive values of raised plasma metal ion levels in the diagnosis of adverse reaction to metal debris in symptomatic patients with a metal-on-metal arthroplasty of the hip. J Bone Joint Surg Br. 2012 Aug;94 (8):1045-50.

12. Sidaginamale RP, Joyce TJ, Lord JK, Jefferson R, Blain PG, Nargol AV, Langton DJ. Blood metal ion testing is an effective screening tool to identify poorly performing metal-on-metal bearing surfaces. Bone Joint Res. 2013;2(5):84-95. Epub 2013 May 16.

13. Van Der Straeten C, Grammatopoulos G, Gill HS, Calistri A, Campbell P, De Smet KA. The 2012 Otto Aufranc Award: the interpretation of metal ion levels in unilateral and bilateral hip resurfacing. Clin Orthop Relat Res. 2013 Feb;471(2): 377-85.

14. Hart AJ, Sabah SA, Sampson B, Skinner JA, Powell JJ, Palla L, Pajamäki KJ, Puolakka T, Reito A, Eskelinen A. Surveillance of patients with metal-on-metal hip resurfacing and total hip prostheses: a prospective cohort study to investigate the relationship between blood metal ion levels and implant failure. J Bone Joint Surg Am. 2014 Jul 2;96(13):1091-9. [Epub ahead of print].

15. Kwon YM, Lombardi AV, Jacobs JJ, Fehring TK, Lewis CG, Cabanela ME. Risk stratification algorithm for management of patients with metal-on-metal hip arthroplasty: consensus statement of the American Association of Hip and Knee Surgeons, the American Academy of Orthopaedic Surgeons, and the Hip Society. J Bone Joint Surg Am. 2014 Jan 1;96(1):e4.

16. Heisel C, Streich N, Krachler M, Jakubowitz E, Kretzer JP. Characterization of the running-in period in total hip resurfacing arthroplasty: an in vivo and in vitro metal ion analysis. J Bone Joint Surg Am. 2008 Aug;90(Suppl 3):125-33.

17. National Joint Registry for England and Wales. 11th annual report. 2014. http://njrcentre.org.uk/njrcentre/Portals/O/Documents/England/Reports/ 11th annual report/NJR\%2011th\%20Annual\%20Report\%202014.pdf. Accessed 2015 Jul 17.

18. Langton DJ, Joyce TJ, Jameson SS, Lord J, Van Orsouw M, Holland JP, Nargol AV, De Smet KA. Adverse reaction to metal debris following hip resurfacing: the influence of component type, orientation and volumetric wear. J Bone Joint Surg Br. 2011 Feb;93(2):164-71.

19. Smith \& Nephew. Birmingham Hip Resurfacing System. 2014. http://www. smith-nephew.com/professional/products/all-products/bhr-birmingham-hipresurfacing/. Accessed 2015 Jul 17.

20. Treacy RB, McBryde $C W$, Pynsent $P B$. Birmingham hip resurfacing arthroplasty. A minimum follow-up of five years. J Bone Joint Surg Br. 2005 Feb;87 (2):167-70.

21. Treacy RB, McBryde CW, Shears E, Pynsent PB. Birmingham hip resurfacing: a minimum follow-up of ten years. J Bone Joint Surg Br. 2011 Jan;93(1):27-33.

22. Matharu GS, Theivendran K, Pynsent PB, Jeys L, Pearson AM, Dunlop DJ. Outcomes of a metal-on-metal total hip replacement system. Ann R Coll Surg Engl. 2014 Oct:96(7):530-5.

23. Dawson J, Fitzpatrick R, Carr A, Murray D. Questionnaire on the perceptions of patients about total hip replacement. J Bone Joint Surg Br. 1996 Mar;78 (2):185-90.

24. Matharu GS, Berryman F, Brash L, Pynsent PB, Treacy RB, Dunlop DJ. Influence of implant design on blood metal ion concentrations in metal-on-metal total hip replacement patients. Int Orthop. 2015 Sep;39(9):1803-11. Epub 2015 Feb 6.

25. Matharu GS, Berryman F, Brash L, Pynsent PB, Treacy RB, Dunlop DJ. Predicting high blood metal ion concentrations following hip resurfacing. Hip Int. 2015 Nov;25 (6):510-9.

26. Kwon YM, Ostlere SJ, McLardy-Smith P, Athanasou NA, Gill HS, Murray DW. "Asymptomatic" pseudotumors after metal-on-metal hip resurfacing arthroplasty: prevalence and metal ion study. J Arthroplasty. 2011 Jun;26(4):511-8. Epub 2010 Jun 29.

27. Hart AJ, Satchithananda K, Liddle AD, Sabah SA, McRobbie D, Henckel J, Cobb JP, Skinner JA, Mitchell AW. Pseudotumors in association with well-functioning metal-on-metal hip prostheses: a case-control study using three-dimensional computed tomography and magnetic resonance imaging. J Bone Joint Surg Am. 2012 Feb 15;94(4):317-25

28. Nishii T, Sakai T, Takao M, Yoshikawa H, Sugano N. Ultrasound screening of periarticular soft tissue abnormality around metal-on-metal bearings. J Arthroplasty. 2012 Jun;27(6):895-900. Epub 2011 Nov 1.

29. Daniel J, Ziaee H, Salama A, Pradhan C, McMinn DJW. The effect of the diameter of metal-on-metal bearings on systemic exposure to cobalt and chromium. J Bone Joint Surg Br. 2006 Apr;88(4):443-8.

30. Harrington CF, Taylor A. Metal-on-metal hip implants. UK quality assurance of blood cobalt and chromium after hip implants. BMJ. 2012;344:e4017. Epub 2012 Jun 12.

31. Davda K, Lali FV, Sampson B, Skinner JA, Hart AJ. An analysis of metal ion levels in the joint fluid of symptomatic patients with metal-on-metal hip replacements. J Bone Joint Surg Br. 2011 Jun;93(6):738-45.

32. Eng J. Receiver operating characteristic analysis: a primer. Acad Radiol. 2005 Jul;12(7):909-16.

33. Robin X, Turck N, Hainard A, Tiberti N, Lisacek F, Sanchez JC, Müller M. pROC: an open-source package for R and S+ to analyze and compare ROC curves. BMC Bioinformatics. 2011 Mar 17;12:77.

34. Coulter G, Young DA, Dalziel RE, Shimmin AJ. Birmingham hip resurfacing at a mean of ten years: results from an independent centre. J Bone Joint Surg Br. 2012 Mar;94(3):315-21.

35. Matharu GS, McBryde CW, Pynsent WB, Pynsent PB, Treacy RB. The outcome of the Birmingham hip resurfacing in patients aged $<50$ years up to 14 years postoperatively. Bone Joint J. 2013 Sep;95-B(9):1172-7.

36. Daniel J, Pradhan C, Ziaee H, Pynsent PB, McMinn DJW. Results of Birmingham hip resurfacing at 12 to 15 years: a single-surgeon series. Bone Joint J. 2014 Oct;96B(10):1298-306.

37. Cooper HJ, Della Valle CJ, Berger RA, Tetreault M, Paprosky WG, Sporer SM, Jacobs JJ. Corrosion at the head-neck taper as a cause for adverse local tissue reactions after total hip arthroplasty. J Bone Joint Surg Am. 2012 Sep 19;94 (18):1655-61. 
626

The Journal of Bone \& Joint Surgery $\cdot$ JBjS. org Volume 98-A • Number $8 \cdot$ April 20, 2016
The Role of Blood Metal Ions in Patients with Unilateral Metal-ON-Metal Hip IMPLANTS
38. Langton DJ, Sidaginamale R, Lord JK, Nargol AV, Joyce TJ. Taper junction failure in large-diameter metal-on-metal bearings. Bone Joint Res. 2012 Apr 1;1 (4):56-63.

39. Langton D. Are metal ion levels a trigger for surgical intervention? In: Jones LC, Greenwald AS, Haggard WO, editors. Metal-on-metal bearings: a clinical practicum. New York: Springer; 2014. p 63-82.

40. Matharu GS, Mellon SJ, Murray DW, Pandit HG. Follow-up of metal-on-metal hip arthroplasty patients is currently not evidence based or cost effective. J Arthroplasty. 2015 Aug;30(8):1317-23. Epub 2015 Mar 14.

41. Reito A, Moilanen T, Puolakka T, Pajamäki J, Eskelinen A. Repeated metal ion measurements in patients with high risk metal-on-metal hip replacement. Int Orthop. 2014 Jul;38(7):1353-61. Epub 2014 Mar 18.
42. Van Der Straeten C, Van Quickenborne D, De Roest B, Calistri A, Victor J, De Smet K. Metal ion levels from well-functioning Birmingham hip resurfacings decline significantly at ten years. Bone Joint J. 2013 Oct;95-B(10):1332-8.

43. Lainiala O, Eskelinen A, Elo P, Puolakka T, Korhonen J, Moilanen T. Adverse reaction to metal debris is more common in patients following MoM total hip replacement with a $36 \mathrm{~mm}$ femoral head than previously thought: results from a modern MoM follow-up programme. Bone Joint J. 2014 Dec;96-B (12):1610-7.

44. Reito A, Puolakka T, Elo P, Pajamäki J, Eskelinen A. Outcome of Birmingham hip resurfacing at ten years: role of routine whole blood metal ion measurements in screening for pseudotumours. Int Orthop. 2014 Nov;38(11):2251-7. Epub 2014 Jul 17. 